\title{
IndAtlas - Technopolitic platform for urban investigation
}

SIGRADI2018

\section{TECHNOPOLITICAS}

xxii congresso da sociedade

iberoamericana de gráfica digital

22th conference of the iberoamerican society

of digital graphics

$07|08| 09 \mid$ novembro|2018

iau usp | são carlos | sp br

Michele Brito

Universidade Federal de Minas Gerais | Brazil | mibrito@dcc.ufmg.br

\section{Ana Isabel de Sá}

Instituto Federal de MG e Universidade Federal de MG | Brazil | ana.sa@ifmg.edu.br

\section{Jéssica Borges}

Universidade Federal de Minas Gerais | Brazil | jessicaborges-ea@ufmg.br

\section{Natacha Rena}

Universidade Federal de Minas Gerais | Brazil | natacharena@gmail.com

\begin{abstract}
This article presents the project of the urban research platform IndAtlas, currently in early development stage by UFMG's Research Group Indisciplinar. Through the association of crowdsourcing tools, a spatial database and the production of visualizations of different types, it is intended to create a Web platform for collecting, analyzing and depicting information about processes of production and transformation of urban space. It is proposed that the phenomena (themes) investigated in the platform are approached mainly from four axes: 1) spatial / territorial; 2) temporal; 3) social; 4) communicational. To do this, we try to combine online collaborative maps with the production of dynamic timelines and visualizations of networks of social actors (graphs), connected with social networks and Wiki pages.
\end{abstract}

The article will address the development of Indisciplinar's working method, which guided the proposal of the platform, as well as the functional and technical aspects to be observed for its implementation, the proposed architecture and the importance of interoperability for the project.

Finally, the inquiries derived from the first test experiment of an IndAtlas test prototype will be presented. The experiment took place in a workshop belonging to the Cidade Eletrônika 2018 Festival - an arts and technology event. The workshop was offered in January of the same year, and it proposed a collaborative cartography of the Santa Tereza neighborhood, in Belo Horizonte / MG - a traditional neighborhood of great importance for historical heritage, currently subject to great real estate pressure and the focus of a series of territorial disputes.

Keywords: IndAtlas, Crowdsourcing, Urban Technopolitics, Digital Cartographies, Spatial Data.

\section{INTRODUÇÃO}

*Obs.: O presente trabalho é uma versão reduzida e adaptada do artigo enviado originalmente para a revista DisegnareCon, atualmente aguardando publicação, com acréscimo dos resultados dos formulários enviados aos participantes do workshop no evento Cidade Eletrônika.

Este trabalho apresenta o projeto da plataforma IndAtlas, atualmente em desenvolvimento pelo Grupo de Pesquisa Indisciplinar. Propõe-se que a plataforma seja composta essencialmente por: 1) mapas colaborativos online; 2) produção de linhas do tempo e infográficos; 3) produção de topologias de redes (grafos); 4) articulação com redes sociais (como Facebook, Twitter, Instagram) e páginas Wiki. Dessa forma, pretende-se reunir em uma mesma aplicação Web as possibilidades de investigar a transformação do território a partir de múltiplos aspectos, contando também com a contribuição cidadã de usuários conectados à Internet, focando particularmente em ferramentas de GIS e VGI.

A ideia de construir a IndAtlas é desdobramento de uma auto-análise da produção do grupo de pesquisa nos últimos cinco anos, concluindo que um de seus pontos chave é justamente a construção de métodos de investigação e ação no espaço urbano (RENA et al., 2016). O Indisciplinar, desde sua fundação, vem buscando explorar taticamente diversos dispositivos tecnopolíticos para a produção de conhecimento de maneira coletiva e colaborativa (cartografias digitais, redes sociais, páginas wiki, linhas do tempo, topologias de redes dos atores etc.), combinando o seu uso com o contato presencial e com a ação direta em determinados grupos e comunidades da sociedade civil. 
O grupo já vem produzindo uma série de análises similares ao que propõe com a plataforma, sob a definição de narrativa cartográfica, mas ainda não conta com uma ferramenta única capaz de relacionar e sobrepor os dados de seus principais eixos de investigação (territorial, temporal, social e comunicacional). Pretende-se, ademais, promover a integração entre as coletas de dados espaciais feitas tanto por pesquisadores quanto por cidadãos comuns, incluindo os usuários dos espaços investigados como protagonistas da produção de conhecimento. Dessa forma, são estabelecidos vários canais de comunicação entre os diversos atores envolvidos na produção e na gestão das cidades.

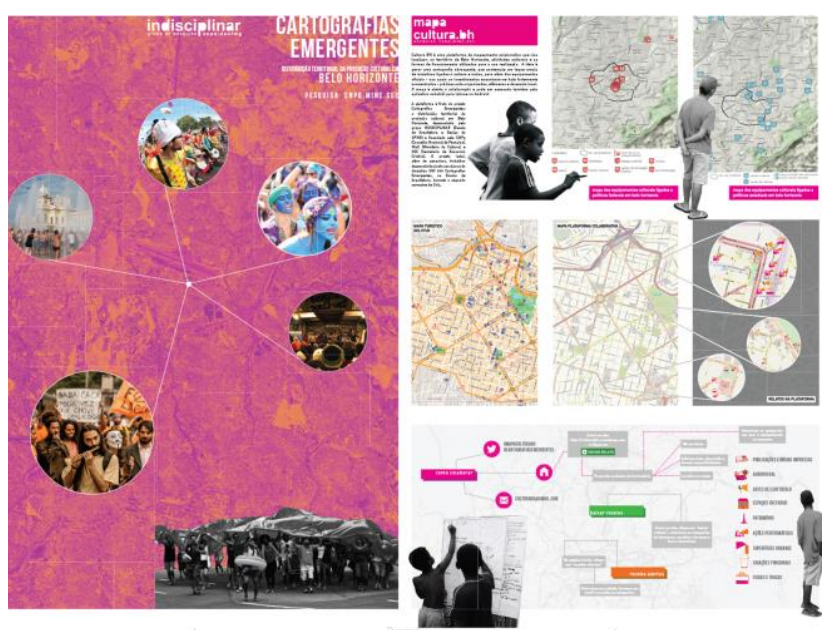

Figura 1: Produção de infográficos do Indisciplinar. Fonte: autores.

Atualmente, o projeto se encontra em fase de desenvolvimento do protótipo de prova. Os primeiros testes com o protótipo foram realizados em janeiro de 2018, em workshop ministrado no evento Cidade Eletrônika, tendo como objeto o bairro de Santa Tereza, em Belo Horizonte/MG - um bairro de caráter bastante tradicional e de grande importância para o patrimônio histórico da cidade, cujo território se encontra sob grande pressão imobiliária e risco de descaracterização.

\section{MÉTODO INDISCIPLINAR E DEFINIÇÃO DOS EIXOS DE ANÁLISE}

Fundado em 2012, o Indisciplinar pesquisa os processos de transformação dos espaços urbanos contemporâneos, com ênfase em situações de disputa territorial envolvendo múltiplos atores sociais. Este contexto abrange desde estudos acerca de grandes projetos urbanos e dos instrumentos legais utilizados para viabilizá-los, até a atuação junto a movimentos como a Rede Verde, envolvida com a luta pela natureza urbana em Belo Horizonte, ou o Salve Santa Tereza, ligado à preservação do patrimônio histórico e cultural no bairro Santa Tereza.

O grupo defende que a Universidade tem um papel fundamental e importância crescente nas disputas urbanas atuais, sobretudo por meio da extensão universitária. Dessa forma, no lugar de se situar como um observador distante ou imparcial, o Indisciplinar se vê como mais um ator intrincado nas redes que atravessam tais conflitos, desempenhando a importante tarefa de auxiliar na decodificação, na tradução e na publicação de informações complexas acerca de tais processos para outros actantes envolvidos. Tal posicionamento dialoga com a Teoria Ator Rede - TAR, de LATOUR (2005), assim como com as noções de cartografia propostas por DELEUZE e GUATTARI (1996), algumas de suas principais referências teóricas. Propõe-se, portanto, atuar no que se identifica como um "ponto cego" das disputas em tela, ou seja: entre os grupos que incidem na esfera micro, ou local, e a macro esfera que envolve o poder público e atores do setor privado atuantes sobre a macro política das questões urbanas. Sob esse aspecto, a produção de informação visual em diversos formatos (visualizações cartográficas, grafos, diagramas, infográficos etc.), como pode ser visto na Figura 1, é de enorme importância, pelo seu poder de sintetizar conteúdos, tornando-os mais acessíveis a públicos não especializados.

A auto avaliação da produção do Indisciplinar até o final do ano de 2015, permitiu concluir que uma das principais potencialidades identificadas foi a produção de um método próprio de trabalho (RENA et al., 2016), o qual combina uma série de dispositivos tecnopolíticos (TORET et al., 2015), possibilitando a produção de conhecimento acerca dos processos investigados de maneira coletiva e compartilhada. Essa reflexão metodológica, portanto, foi justamente 0 que desencadeou a proposta de desenvolvimento da IndAtlas, uma vez que levou a apontar a necessidade de se unificar, conectar e compatibilizar as ferramentas utilizadas em busca de uma maior integração dos dados e das análises produzidos pelo grupo.

O artigo "Grupo de Pesquisa Indisciplinar: método, ativismo e tecnopolítica na defesa dos bens comuns urbanos" (RENA et al., 2016) detalha essa auto-análise e sistematização do método de trabalho. Em linhas gerais, concluiu-se que a produção do grupo se articula a partir de quatro eixos de análise e ação - territorial, temporal, social (redes de atores) e comunicacional -, organizando-se a partir de: a) mapas colaborativos georreferenciados (sendo a plataforma de crowdsourcing Crowdmap/Ushahidi a escolha adotada com maior frequência até aquele momento); b) páginas Wiki; c) componentes de redes sociais (fanpage no Facebook, Twitter etc.); d) produção de linhas do tempo, infográficos e cartilhas.

Por um lado, a utilização dessas diferentes interfaces vinha proporcionando ao grupo o desenvolvimento de um método capaz de abordar seus objetos de análise sob os referidos aspectos, sempre buscando o maior nível possível de interação e comunicação em rede com os atores articulados em cada processo. A adoção de múltiplos canais e a ausência de conectividade entre alguns deles, entretanto, tem imposto desafios como trabalho duplicado, perda de informações e dispersão de dados, justificando o desejo de integração dessas funcionalidades em uma única plataforma de VGI "Volunteer Geographic Information" (GOODCHILD, 2007) de código aberto, a IndAtlas - uma vez que se acredita no grande potencial de aplicação da plataforma em investigações ou propostas urbanas de variadas naturezas, muito mais abrangentes do que o universo das pesquisas do grupo Indisciplinar. A tabela abaixo lista as principais potencialidades e limitações identificadas nessa forma de trabalho: 
Tabela 1: potencialidades e limitações do método Indisciplinar

\begin{tabular}{|c|c|}
\hline Potencialidades & Limitações / Desafios \\
\hline $\begin{array}{l}\text { Uso tático de ferramentas } \\
\text { tecnopolíticas disponíveis }\end{array}$ & $\begin{array}{l}\text { Falta de interoperabilidade e } \\
\text { feedback entre diferentes } \\
\text { plataformas utilizadas }\end{array}$ \\
\hline $\begin{array}{l}\text { Produção coletiva e } \\
\text { colaborativa de conhecimento } \\
\text { acerca da produção do } \\
\text { espaço urbano. Engajamento } \\
\text { direto com atores e } \\
\text { comunidades envolvidos nos } \\
\text { processos em tela. }\end{array}$ & $\begin{array}{l}\text { Perda de trabalho (ou } \\
\text { retrabalho) e de dados devida } \\
\text { ao uso de muitos sistemas } \\
\text { diferentes e desconectados }\end{array}$ \\
\hline $\begin{array}{l}\text { Tradução de conteúdos } \\
\text { complexos em formatos mais } \\
\text { acessíveis ao público em } \\
\text { geral - atuação no "ponto } \\
\text { cego" das disputas territoriais }\end{array}$ & $\begin{array}{l}\text { Necessidade de unificar } \\
\text { bases de dados e de } \\
\text { promover análises de dados } \\
\text { em volumes mais robustos }\end{array}$ \\
\hline $\begin{array}{l}\text { Produção gráfica potente } \\
\text { capaz de combinar múltiplas } \\
\text { formas de visualização } \\
\text { (mapas, } \\
\text { infográficos, grafos) }\end{array}$ & $\begin{array}{l}\text { Necessidade de visualizações } \\
\text { mais dinâmicas e } \\
\text { constantemente atualizadas }\end{array}$ \\
\hline & $\begin{array}{l}\text { Desejo de poder fornecer } \\
\text { dados em formato bruto, ou } \\
\text { em forma de IDE a parceiros } \\
\text { e/ou outros grupos de } \\
\text { pesquisa }\end{array}$ \\
\hline
\end{tabular}

A partir das fragilidades e potências identificadas acima, propôs-se o primeiro esboço de desenho conceitual da plataforma. Foram tomados como pontos de partida tanto os tipos de informação a serem recebidos e processados (inputs), e os formatos de saída e apresentação dessa informação após seu tratamento e análise (outputs), quanto os diversos componentes a serem conectados.

Compreende-se que do ponto de vista operacional, a plataforma proposta se baseia essencialmente em dois princípios fundamentais: 1) sua estruturação como um serviço de Web, 2) a necessidade de interoperabilidade entre os componentes. Dessa forma, cabe abordar tais aspectos de maneira mais ampla visando compreender sua aplicação mais específica no projeto da IndAtlas. Ao final do projeto espera-se o desenvolvimento de uma plataforma única que seja capaz de prover mecanismos de coleta de dados sobre as relações entre os atores que influenciam mudanças no espaço físico ao longo do tempo. Ou seja, uma única aplicação para coleta e análise dessas variáveis.

\section{ARQUITETURA DA PLATAFORMA INDATLAS}

A arquitetura proposta para a IndAtlas se estrutura a partir de três camadas: Persistência, Negócios e Aplicação. Para isso, adota-se o padrão introduzido por Fielding (2000), que define que os componentes das camadas possam implementar funções específicas dentro de um escopo geral. Por exemplo, os componentes da camada de Persistência têm o papel de armazenar os dados produzidos e consumidos pela aplicação. Já a camada de Negócios, por sua vez, recebe esse nome pois seus elementos são responsáveis por mediar as requisições da camada de Aplicação aos dados armazenados na camada de Persistência. Por fim, os elementos da camada de Aplicação, como o próprio termo propõe, consistem na aplicação final com que o usuário interage diretamente, podendo constituir uma aplicação Web ou mobile.

\section{PERSISTÊNCIA}

Como citado anteriormente, a camada de Persistência contém os componentes responsáveis pelo armazenamento dos dados a serem utilizados no sistema como um todo. Um dos pontos importantes da camada de persistência é a definição da estrutura dos dados que serão armazenados. Partindo da análise do método de pesquisa do Indisciplinar, e do objeto de pesquisa, que inclui a relação entre sociedade e espaço urbano, chegouse à conclusão que a melhor forma de representar esse contexto seria por meio de uma estrutura em grafo, que por sua vez, corresponderia às características dessa rede complexa.

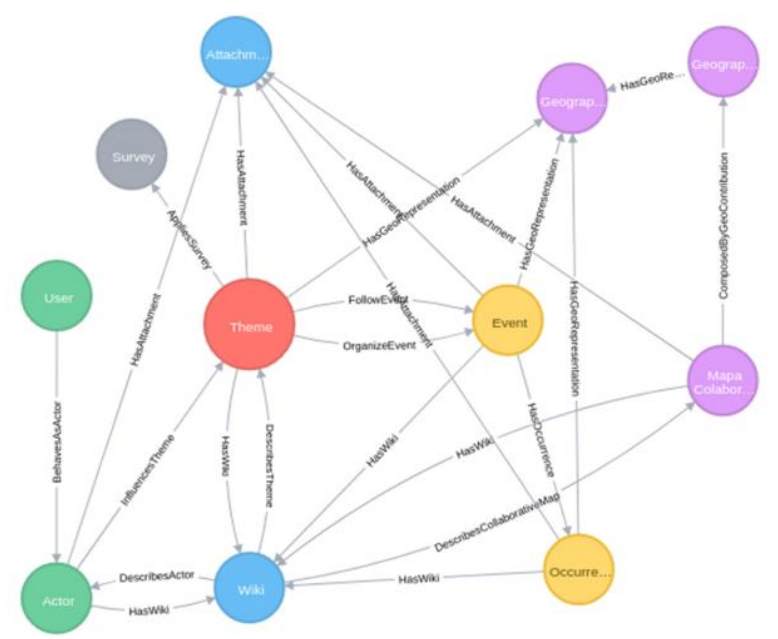

3

Figura 2: Estrutura conceitual do banco de dados. Fonte: autores.

Dessa forma, a modelagem da estrutura do banco de dados (Figura 2) consiste na identificação das entidades que seriam representadas pelos nós da rede e por seus relacionamentos. Inicialmente, estão identificados onze tipos de entidades (nós): Tema, Ator, Usuário, Mapa Colaborativo, Contribuição Geográfica, Questionário, Representação Geográfica, Anexo, Wiki, Evento e Acontecimento - assim como um conjunto inicial de relacionamentos. Posteriormente, esse conjunto inicial de relações apresentado no modelo pode se expandir, a partir do momento em que outros tipos de análises sobre os Temas sejam apresentados.

Nesse contexto, Tema é a principal entidade do modelo, representando o principal objeto de estudo de um conjunto específico de pesquisadores, e as demais entidades se organizam ao seu redor (como se o tema correspondesse a cada projeto/iniciativa de cartografia). Os nós de Atores possibilitam cartografar os diferentes atores sociais (humanos ou não-humanos) que se articulam, incidindo de alguma forma sobre o Tema investigado. Os Eventos, por sua vez, estruturam a dimensão temporal da análise, 
conformando uma linha do tempo de acontecimentos e transformações. A um Tema também poderão ser associados Mapas Colaborativos e Questionários customizados, voltados a coletar informações específicas a cada projeto. Adicionalmente, grande parte das informações coletadas podem ser complementadas por meio de Anexos como imagens, áudios e vídeos, assim como a Representação Geográfica de certos elementos, como a área sobre a qual o Tema incide.

\section{NEGÓCIOS}

A camada de negócios é aquela responsável por intermediar as transações entre os componentes da camada de Aplicação e a camada de Persistência. Ela tem, portanto, dois tipos principais de função: 1) restringir o acesso aos dados, ou à parte deles, podendo ser utilizada como uma camada de segurança, e 2) definir o padrão em que os dados serão disponibilizados para as aplicações da camada acima.

A camada de Negócios pode conter uma miríade de serviços que podem atender a diversos componentes da camada de aplicação. Assim sendo, foram planejados dois tipos diferentes de serviços: o primeiro atendendo especificamente a aplicações Web ou mobile responsáveis pela entrada de dados por meio de crowdsourcing ativo - e o segundo oferecendo uma interface para divulgação e compartilhamento de dados entre grupos de pesquisa.

Para o desenvolvimento da API, foram planejados endpoints responsáveis pelo padrão de operações de CRUD (Create, Retrieve, Update e Delete) dos nós listados na seção de persistência, assim como a atribuição de seus relacionamentos. Além disso, planeja-se que o conjunto total de operações seja disponibilizado sobre os usuários que utilizam as aplicações da camada acima de forma seletiva. Ou seja, devem ser definidos grupos de usuários que podem ou não utilizar um determinado conjunto de operações, garantindo a segurança dos dados. Por meio dessa hierarquia, é possível distinguir entre usuários comuns, que realizaram operações básicas de criação de informações sobre os temas, mas que não tem o poder de visualizar, criar ou alterar informações sensíveis, restritas aos administradores.

Outro ponto importante da API é o ambiente em que ela será desenvolvida. Planeja-se a utilização do ambiente em Python, utilizando Flask como framework para seu desenvolvimento. Um dos motivos que levaram a essa escolha é sua fácil configuração, além de ser portátil e bem documentado. Além disso, o ambiente conta com outros tipos de ferramentas de análise que podem ser utilizados na concatenação de dados a serem exibidos pelas visualizações, presentes nos respectivos elementos da camada de aplicação.

\section{APLICAÇÃO}

É na camada de Aplicação que estão situadas as aplicações do sistema como um todo. Novamente, como um efeito da arquitetura em camadas, é possível que diferentes tipos de aplicação sejam implementados, utilizando os recursos de componentes das demais camadas. Dessa forma, a camada pode contar com qualquer tipo de aplicação que faça uso dos dados disponibilizados utilizando o padrão OGC (como Web mappings ou QuantumGIS), assim como a aplicações desenvolvidas no projeto para coleta das informações de forma ativa pelos integrantes de um grupo específico de usuários, que eventualmente utilizem o sistema.

Para a aplicação de coleta de dados é prevista a mistura entre funcionalidade de CRUD, na qual os formulários tradicionais para a coleta de informação figuram, junto às visualizações produzidas, para a análise visual das informações. Pensando nas funcionalidades e nos requisitos da aplicação, o projeto conta com a utilização da biblioteca para construção de componentes ReactJS, associada à biblioteca de controles de estados Redux. Ambas as bibliotecas apresentam uma grande flexibilidade e reuso de componentes de UI (User Interface), permitindo que os mesmos possam ser reutilizados e reapresentados em diversas seções da interface da aplicação.

No que tange o conjunto de visualizações, pretende-se utilizar a biblioteca D3, amplamente utilizada em visualizações Web que possui, portanto, extensa documentação., Além disso, ela também é extremamente flexível, permitindo a construção de visualizações que vão além de simples gráficos, podendo ser utilizada nas visualizações de linhas do tempo e grafos. Em conjunto com a biblioteca D3, pretende-se utilizar a biblioteca Leaflet para a construção dos mapas Web, também por sua flexibilidade e por apresentar diversos plugins implementados pela comunidade de desenvolvedores, que adicionam outras funcionalidades aos mapas.

\section{RESULTADOS PRELIMINARES}

Uma primeira experiência de teste do protótipo de prova (Figura 3), foi conduzida em janeiro de 2018, durante um workshop no evento Cidade Eletrônika, em Belo Horizonte, cujos resultados serão de grande valia para as etapas subsequentes do projeto. $O$ workshop ocorreu durante dois dias, com a participação de 10 inscritos - em sua maioria, estudantes de arquitetura e urbanismo de várias localidades do Brasil -, tendo como tema o bairro de Santa Tereza e as transformações a que seu território vem sendo submetido.

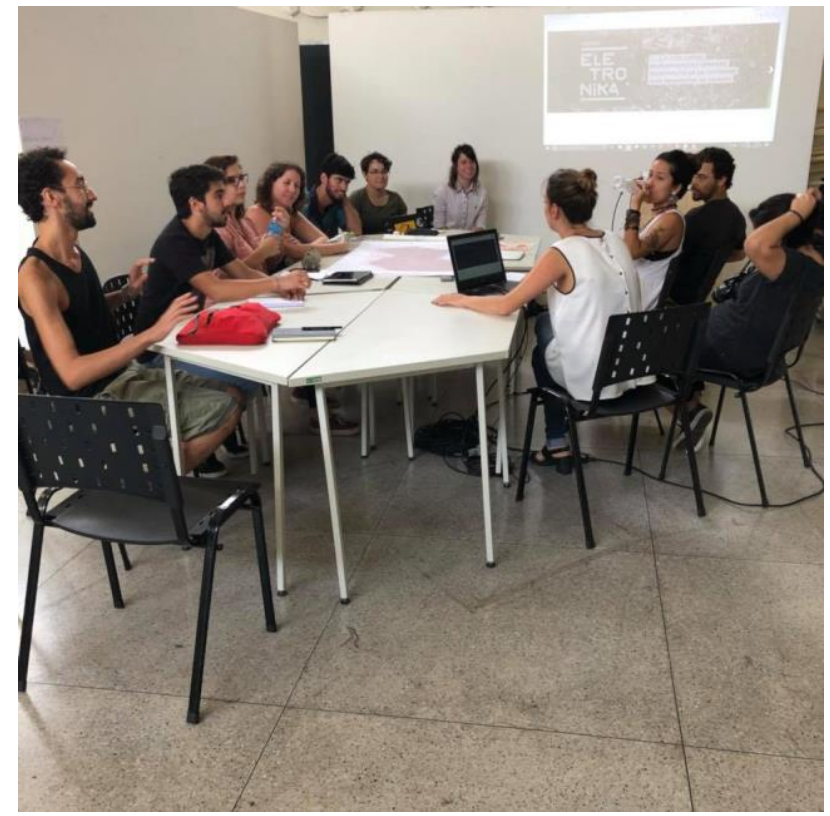

Figura 3: Rodada de apresentação da ferramenta no workshop Cidade Eletrônika. Fonte: autores. 
Santa Tereza é um dos bairros mais tradicionais de Belo Horizonte, cuja ocupação inicial remonta ao período de fundação da cidade. Ao longo das décadas, o bairro desenvolveu uma vocação para abrigar atividades artísticas de diversos tipos e para a vida boêmia, tendo sido o local de origem de movimentos culturais e grupos musicais de grande expressividade nos cenários mineiro e nacional. Do ponto de vista do patrimônio construído, encontram-se no bairro várias edificações de valor histórico e, sob o aspecto da paisagem natural, destaca-se um campo de visada da Serra do Curral ainda preservado. Acrescentando à complexidade do contexto, Santa Tereza abriga a Vila Dias, caracterizada pela legislação urbana vigente como ZEIS (Zona Especial de Interesse Social), onde vive uma população de baixa renda, em situação de grande fragilidade social.

Boa parte do bairro é hoje classificada pela Lei de Uso e Ocupação do Solo como uma ADE - Área de Diretrizes Especiais -, o que impõe uma série de restrições a seus parâmetros de ocupação, justamente pela sua importância para o patrimônio histórico da cidade. Santa Tereza, contudo, encontra-se em uma região estratégica para o mercado, no coração de uma Operação Urbana em discussão, e vem sofrendo grande pressão imobiliária. Vários GPUs (Grandes Projetos Urbanos) vêm sendo propostos para a área, causando grande controvérsia entre os moradores ou movimentos voltados à preservação do bairro como o Salve Santa Tereza.

O workshop propôs, portanto, realizar uma cartografia dos processos de transformação e das disputas em curso no bairro, testando a coleta de três tipos principais de informação: Eventos (linha do tempo), Atores (grafos) e Localizações Geográficas (mapa colaborativo). Os participantes definiram 7 principais temas para cartografar, dividindo-se entre eles a partir de seus interesses específicos, sendo os temas: 1) instituições; 2) GPUs / empreendimentos imobiliários; 3) cultura; 4) vazios urbanos; 5) patrimônio histórico; 6) lugar de encontro ou mobilização da sociedade civil; 7) natureza urbana. Além do protótipo de prova da IndAtlas, foram utilizados como suporte mapas (Figura 5) e linhas do tempo impressos (Figura 6), que auxiliaram nos momentos de discussão coletiva e de organização prévias dos aspectos cartografados.

O protótipo simples concebido buscou avaliar conceitualmente a interação entre esses três tipos de informação, assim como a forma com que as mesmas são dispostas aos usuários sobre a forma de visualizações. O protótipo aglutinava, portanto, um conjunto de ferramentas e bibliotecas que seriam de fácil e rápido desenvolvimento. Dessa forma, para a coleta, armazenamento publicação dos dados, foi utilizado o Google Spreadsheet, e para as visualizações foram utilizados o TimelineJS. Para a criação de linhas do tempo, utilizou-se o LeafletJS para a entrada e exibição de dados georreferenciados, e o SigmaJS foi usado para a exibição do grafo de atores. A figura 4 ilustra como as informações coletadas são visualizadas na interface do protótipo.

Embora ainda não tenhamos desenvolvido uma estrutura sistematizada para o uso da plataforma em diferentes situações (que consideramos fundamentais para a próxima etapa do projeto), a proposta era que o workshop seguisse as etapas listadas abaixo:
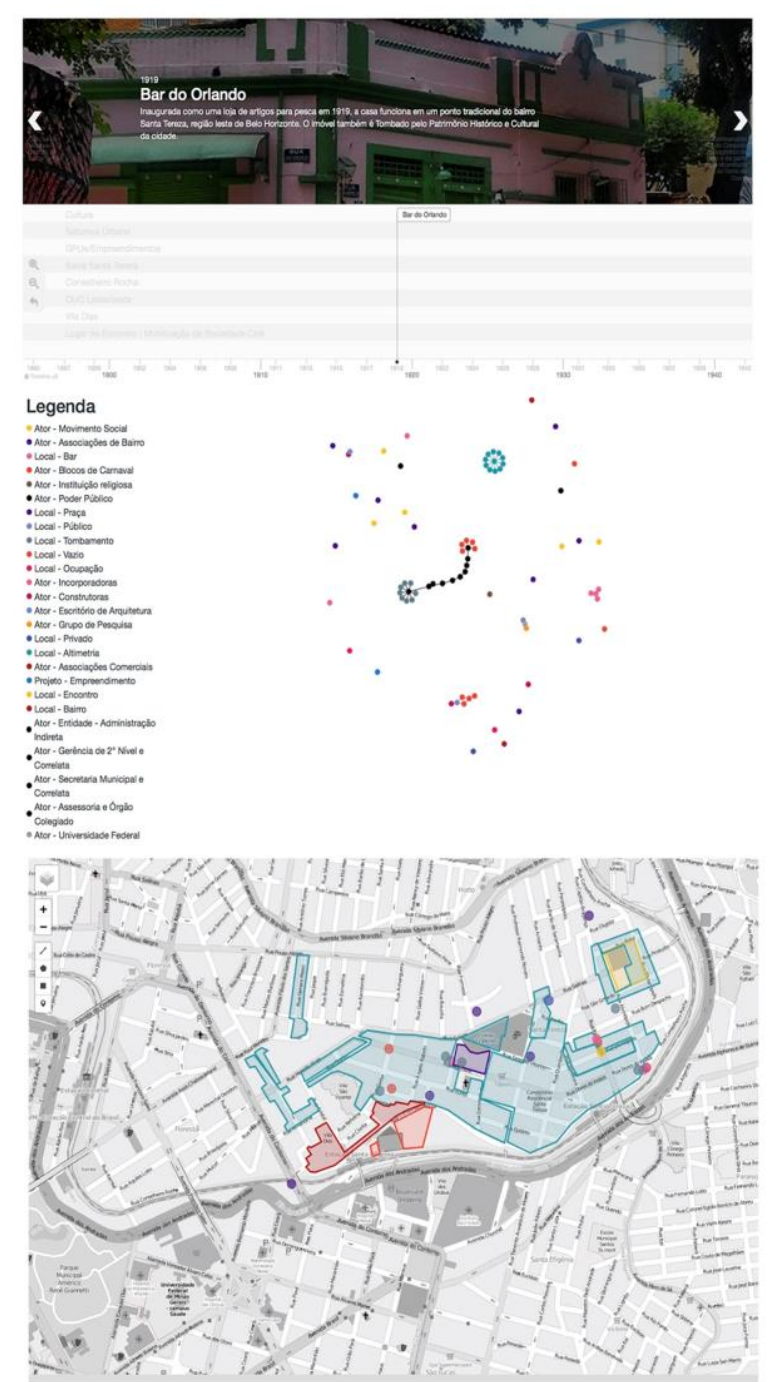

Figura 4: Visão geral do protótipo avaliado. Fonte: autores.

\section{Dia um:}

1. Apresentação geral dos participantes e "brainstorm" sobre o bairro. Apresentação da interface de visualização da IndAtlas e da planilha a ser preenchida (duração: aproximadamente 1 hora)

2. Divisão de equipes por categoria. Marcações iniciais em mapas impressos, linha do tempo e ferramentas on-line, com base no conhecimento prévio da equipe sobre a área (duração: aproximadamente 1 hora)

3. Levantamento de informações a serem coletadas no campo e / ou online (duração: aproximadamente 2 horas)

\section{Dia dois:}

1. Visão geral das informações coletadas no primeiro dia por cada equipe e definição de informações adicionais a serem coletadas no campo ou on-line (duração: aproximadamente 1 hora) 
2. Continuidade da coleta de dados em campo e on-line e do preenchimento dos gráficos do mapa / linha do tempo / e do ator na plataforma (duração: aproximadamente 2 horas)

3. Partilha e discussão dos resultados do trabalho de cada grupo (duração: aproximadamente 1 hora)

Como será discutido na seção de comentários finais, o número de participantes e a composição dos grupos foram muito diferentes do que esperávamos - já que tínhamos planejado trabalhar principalmente com grupos mais envolvidos com a área de estudo, o que deveria simplificar os momentos de coleta de dados e permitir mais tempo para os processos de se familiarizar com a plataforma e de produzir as visualizações.

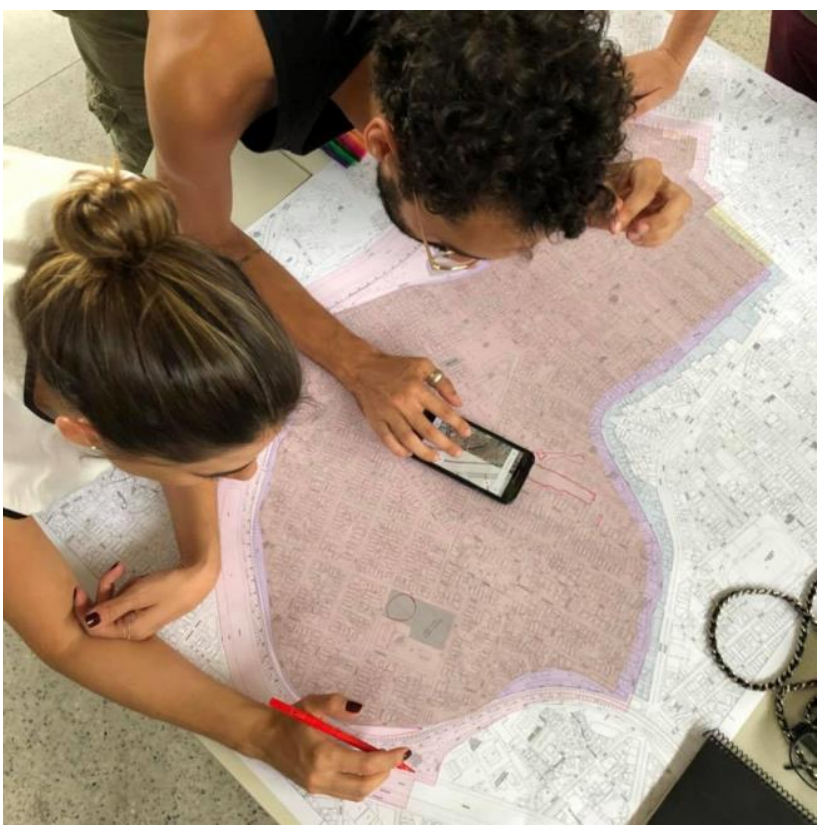

Figura 5: Processo analógico para auxiliar o processo de coleta de informações no trabalho da equipe. Fonte: autores.

Após o workshop, os participantes receberam um questionário, que foi respondido por $50 \%$ dos presentes. 0 questionário continha as seguintes questões: 1) $\mathrm{O}$ que te levou a participar do workshop do Cidade Eletrônika sobre Santa Tereza?; 2) Você já tinha algum conhecimento / envolvimento prévio com o bairro Santa Tereza? Se sim, qual? 3) Você já tinha tido alguma experiência anterior com ferramentas/processos de mapeamentos digitais colaborativos? Se sim, quais? 4) Do seu ponto de vista, o protótipo da plataforma IndAtlas utilizado no workshop contribui para o exercício de cartografia proposto? De que maneiras?; 5) Quais diferenças você identificou entre o protótipo utilizado no workshop e outras ferramentas similares que já tivesse utilizado anteriormente? Quais potencialidades ou deficiências ele apresenta em relação a outras plataformas disponíveis online?; 6) Você encontrou alguma dificuldade na utilização da plataforma? Qual(is)?; 7) Você teria alguma sugestão para a continuidade do desenvolvimento da plataforma? Qual(is)?.

Com relação à motivação para participação (com possibilidade de selecionar mais de uma alternativa), $100 \%$ dos participantes demonstraram interesse por conhecer melhor o método cartográfico do grupo Indisciplinar; 80\% afirmaram ter interesse por ferramentas de mapeamento colaborativo digital em geral; e apenas $60 \%$ relataram ter algum envolvimento prévio ou interesse pelo Bairro de Santa Tereza. Dentre os participantes que reportaram ter envolvimento prévio com o Bairro, apenas $20 \%$ afirmaram morar ou já ter morado no local; $20 \%$ afirmaram ter interesse no Bairro como objeto de pesquisa; e $20 \%$ disseram não morar, mas frequentar o bairro eventualmente.

No que diz respeito à familiaridade anterior com mapeamentos colaborativos digitais, apenas $40 \%$ dos participantes responderam afirmativamente. Outros 40\% não relataram ter nenhuma experiência com ferramentas digitais, mas já haviam participado de ou organizado processos de mapeamentos colaborativos "analógicos". Um dos participantes afirmou não ter tido nenhum tipo de contato anterior ao workshop, mas de ter buscado essa experiência posteriormente.

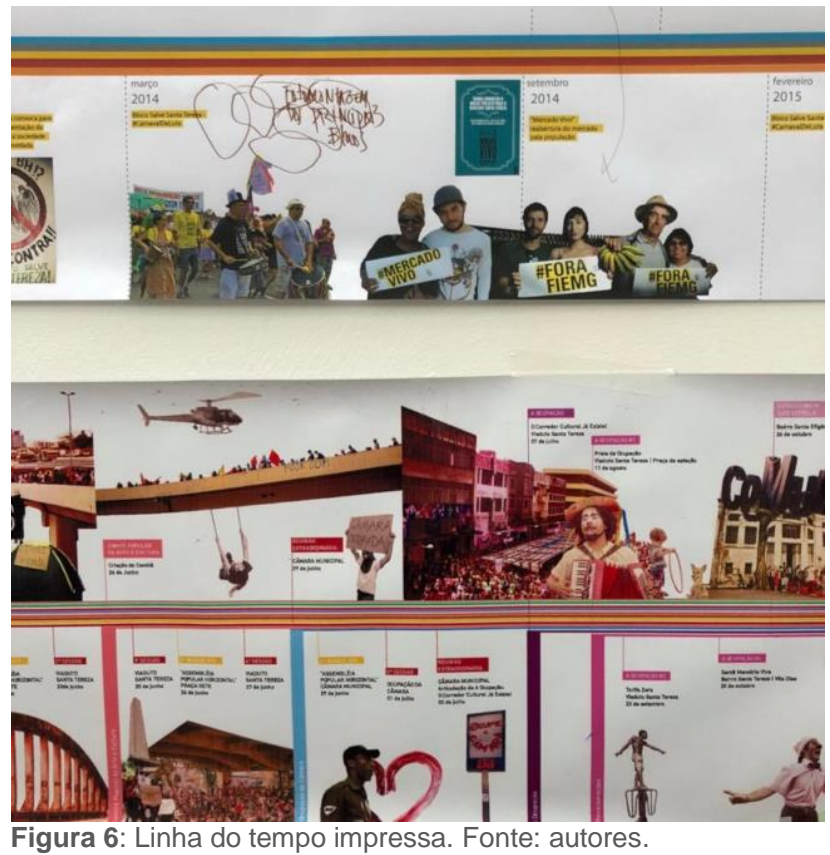

Todos os entrevistados afirmaram achar que o uso da plataforma contribuiu para o exercício de cartografia proposto, destacando sobretudo a facilidade de visualização dos dados em formatos distintos (grafos, mapa e linha do tempo), porém apresentados simultaneamente. Essa característica foi reforçada na questão seguinte, sobre potencialidades e deficiências da plataforma, somada à divisão da linha do tempo em "trilhos" temáticos. Por outro lado, a falta de contraste da linha do tempo, a dificuldade de associar imagens à mesma, e o caráter bastante abstrato da visualização dos grafos foram apontados como deficiências - aspectos que deverão ser abordados na continuidade do desenvolvimento da IndAtlas.

Já durante o workshop, vários participantes relataram algumas dificuldades sobretudo para entender os procedimentos de preenchimento das planilhas Google Spreadsheet e as maneiras como suas abas se conectam umas às outras e à interface de visualização. No entanto, apenas um dos participantes relatou tal dificuldade no 
formulário, o que leva a crer que o contato com a plataforma ajudou a superar o estranhamento inicial. Tal dificuldade era previsível, uma vez que a solução da entrada de dados via planilhas é provisória e que já se planejava concentrar grandes esforços nas próximas etapas do trabalho com o desenvolvimento e o design de interação da camada de aplicação. Além desse aspecto, o tempo curto de realização do workshop também foi mencionado, assim como a dificuldade em criar novas categorias de nós que não tivessem sido previstas anteriormente. Foi sugerido que vídeo aulas com tutoriais de como usar a plataforma fossem enviados aos alunos antes dos workshops, uma etapa que pode ser estudada em eventos futuros.

Dentre as demais sugestões para a continuidade da plataforma, foram citadas: a diferenciação das trilhas da LT com cores diferentes; a articulação mais direta entre os atores apresentados nos grafos e a análise temporal (ou seja, que os atores e suas conexões sejam visualizados sempre em relação aos momentos em que estão de fato incidindo sobre o Tema em tela); e a elaboração de um passo-a-passo para a utilização da IndAtlas.

Ainda no evento, os participantes foram questionados sobre o entendimento das visualizações produzidas e não reportaram ter encontrado dificuldades, considerando fácil compreender as conexões entre os dados apresentados nos mapas, na linha do tempo e no grafo de atores. Cabe ressaltar que o grupo era composto essencialmente por alunos de Arquitetura e Urbanismo, usualmente mais habituados à representação cartográfica. Considera-se fundamental repetir os testes com grupos mais diversificados, que incluam usuários não especialistas.

Finalmente, cabe ressaltar uma contribuição surgida no workshop que pode gerar desdobramentos futuros de bastante potencial para a plataforma. Trata-se da sugestão de se investigar a possibilidade de atrelar não somente os relatos coletados, mas também a base cartográfica do mapa colaborativo à linha do tempo, modificando-a a partir da navegação temporal. Assim, seriam representadas as transformações da malha urbana ao longo dos anos e sua relação com os eventos ocorridos. Entende-se que tal recurso pode futuramente acrescentar uma camada de análise valiosa às visualizações criadas pela IndAtlas, mas ainda há que se averiguar as repercussões técnicas da produção e da incorporação de tais bases.

\section{CONSIDERAÇÕES FINAIS}

Sob o ponto de vista do desenvolvimento da plataforma, o teste do protótipo de provas no workshop constituiu um importante passo, mesmo com a pesquisa ainda em fase inicial. Tratou-se da primeira vez em que os componentes e funcionalidades propostos foram submetidos à utilização por um público externo à sua equipe de elaboração, possibilitando que se registrasse um retorno valioso acerca de potencialidades e dificuldades encontradas em sua utilização.

Uma limitação recorrente em processos de crowdsourcing que se pôde identificar no workshop, e que também reflete na composição de seus integrantes, é justamente a questão da mobilização para participar de projetos do tipo. A dificuldade em promover o engajamento se revelou novamente nessa ocasião quando, por exemplo, dos mais de 30 inscritos inicialmente no workshop, apenas 10 pessoas efetivamente compareceram e participaram das atividades. Isso foi agravado por questões externas ao controle da equipe do projeto, como a definição da data do evento, modificada sucessivamente e divulgada com pouca antecedência. A data final coincidiu com o período de férias escolares, o que desestimulou sobretudo a participação de moradores de Santa Tereza e de atores dos movimentos e dos projetos ligados ao bairro - ainda que muitos desses venham atuando em parceria com o Grupo Indisciplinar em diversas ações anteriores.

Nesse sentido, as condições criadas favoreceram a participação de estudantes da área, que aproveitaram as férias letivas para comparecer ao evento. Se por um lado isso facilitou a compreensão do método e das ferramentas pelo grupo testado, por outro prejudicou aspectos importantes como a análise das redes de atores envolvidos nos processos de produção espacial do bairro. Isso também teve impacto sobre a dinâmica inicial proposta para o workshop, uma vez que demandava um esforço maior para se dedicar à coleta e organização de dados, comprometendo o tempo restante para o uso real da plataforma. Como a maior parte dos participantes não tinha uma relação prévia significativa com o território investigado, não conseguiram contribuir muito com essa dimensão de análise.

Entende-se, dessa forma, que nas situações em que a plataforma for utilizada em situações de cartografia coletiva (pois vislumbra-se também o seu uso como uma ferramenta interna para a coleta, organização e apresentação de dados de grupos de pesquisa), é preciso estabelecer também um framework metodológico para sua utilização. A definição prévia da composição de participantes adequado a cada situação, assim como dos mecanismos a serem utilizados para mobilizar a sua colaboração, são etapas cruciais desse quadro. Como essa foi a primeira oportunidade para testar o protótipo, ainda não tínhamos muita clareza sobre quais eram os principais aspectos para orientar a articulação dessa dinâmica. Acreditamos também que propor frameworks alternativos para aplicação distinta do IndAtlas é bastante importante - por exemplo: projetos em que a plataforma é utilizada para desenvolver uma cartografia da situação atual de uma área devem ter um arcabouço diferente de propostas que surgiram usar o IndAtlas para dar suporte a um processo de Codesign, no qual uma abordagem propositiva de qualquer nível está presente. Avançar na definição de tais etapas e das táticas para o uso da plataforma em cartografias coletivas é um aspecto tão importante ao projeto quanto 0 desenvolvimento ferramental. Ambos devem ocorrer e evoluir simultaneamente.

O desenvolvimento da plataforma após o workshop de janeiro já eliminou o preenchimento dos dados por meio de planilha, e avançou no tratamento gráfico da interface, apesar de ainda estar pendente a entrada de um pesquisador da área de Design na equipe do projeto, que será responsável pelos avanços mais efetivos nesse sentido. Estão previstas duas novas oportunidades de teste da versão atual da plataforma no segundo semestre de 2018, em duas disciplinas de graduação dos cursos de Arquitetura e Urbanismo da UFMG, e do IFMG. 


\section{AGRADECIMENTOS}

Agradecemos ao apoio dos nossos programas e projetos; ao GEOPROEA - UFMG (Laboratório de Geoprocessamento da Escola de Arquitetura da UFMG), coordenado pela Profa. Dra. Ana Clara Moura; ao laboratório CS + X do DCC-UFMG, coordenado pelo Prof. Dr. Clodoveu Davis; ao PRPq e PROEX da UFMG; e ao IFMG Campus Santa Luzia. Agradecemos à equipe de produção do evento Cidade Eletrônika 2018 e aos participantes do workshop que possibilitaram os testes do protótipo da plataforma IndAtlas. Finalmente, deixamos nossos mais sinceros agradecimentos a todos os colegas pesquisadores do Indisciplinar que tornam todos os nossos trabalhos coletivos, e estão presentes em nossas cartografias de múltiplos modos.

\section{REFERÊNCIAS}

Burrough, P. A., McDonnell, R. A., \& Lloyd, C. D. (2015). Principles of geographical information systems. Oxford University Press.

Deleuze, G. (2000). Mil platôs: capitalismo e esquizofrenia (Vol. 5). Editora 34.

Fielding, R. T., \& Taylor, R. N. (2000). Architectural styles and the design of network-based software architectures (Vol. 7). Doctoral dissertation: University of California, Irvine.

Reed, C. (2011). OGC standards: Enabling the geospatial web. Advances in Web-based GIS, Mapping Services and Applications, 9, 327.

Latour, B. (2005). Reassembling the social: An introduction to actor-network-theory. Oxford university press.

Oliveira, P. A., Junior, C. A. D., \& Oliveira, P. F. A. (2008). Proposição de Infra-Estrutura de Dados Espaciais (SDI) Local, Baseada em Arquitetura Orientada por Serviços (SOA). URL [On line]: http://www. geoinfo. info/geoinfo2008/papers/p61. pdf. Access in: Dec, 1.

RENA, Natacha; SÁ, ANA ISABEL; FRANZONI, Julia; BRANDÃO, Marcela S.;. Grupo de Pesquisa Indisciplinar: método, ativismo e tecnopolítica na defesa dos bens comuns urbanos. URL [On line]: <http://contested-cities.net/workingpapers/2016/grupo-de-pesquisa-indisciplinar-metodoativismo-e-tecnopolitica-na-defesa-dos-bens-comunsurbanos/>. Acess in: March, 23. 